đổi về tình trạng vi khuẩn gây bệnh trong mảng bám dưới lợi ở người hút thuốc lá cũng làm ảnh hưởng đến tình trạng bệnh viêm quanh răng. Kết quả từ nghiên cứu này cho thấy có mối liên quan chặt chẽ của hệ vi khuẩn gây bệnh dưới lợi với tình trạng hút thuốc, đặc biệt là với $A$. actinomycetemcomitans (OR là 7,50). Kết quả này cũng tương tự như kết quả của Winkelhoff A.J (2001) (5). Độ sâu túi quanh răng trung bình và độ mất bám dính quanh răng lâm sàng của nhóm hút thuốc lá cao hơn đáng kể so với nhóm không hút thuốc $(p<0,05)$. Kết quả này phù hợp với kết luận của các tác giả khác (4).

Tình trạng tích tụ mảng bám răng và số lượng túi quanh răng sâu trên $5 \mathrm{~mm}$ của nhóm hút thuốc lá trầm trọng hơn nhóm không hút có ý nghĩa thống kê với $p<0,05$. Điều này cũng phù hợp với kết luận của các tác giả khác và chứng tỏ rằng hút thuốc lá là yếu tố nguy cơ chỉ điểm cho tình trạng trầm trọng của bệnh VQR (3).

Các nhà nghiên cứu cũng thấy rằng mặc dù tốc độ tích tụ mảng bám của người hút thuốc và không hút tương đương nhau, nhưng tốc độ tăng tuần hoàn lợi ở người hút thuốc chỉ bằng một nửa so với người không hút thuốc [3]. Hậu quả là gây ảnh hưởng ngụy trang trên các triệu chứng viêm và có thể dẫn đến kết luận hút thuốc lá không có nguy cơ làm tăng chảy máu lợi. Trong nghiên cứu này, tỷ lệ chảy máu lợi của nhóm không hút thuốc cao hơn nhóm hút thuốc đáng kể $(72,9 \%$ và $27,1 \%)$. Kết quả này phù hợp với kết quả nghiên cứu của Van der Weijden và công sứ (2001) là không có sự khác biệt về mức độ chảy máu lợi giữa nhóm hút thuốc và không hút thuốc măcc dù nhóm hút thuốc có có túi lợi sâu hơn hoặc tích tụ nhiều mảng bám hơn[5].
Nhiêu nghiên cứu cho thấy, người mắc viêm quanh răng thường già hơn và là nam giới (6). Nhận xét này cũng phù hợp với kết quả của nghiên cứu này. Tỷ lệ mắc bệnh của người trên 35 tuổi cao hơn đáng kể so với lứa tuối trẻ hơn với $O R$ (độ tin cậy $95 \%$ ) là 4,25 và $p<0,01$. Tuy nhiên, có thể chính sự phơi nhiễm với các yếu tố nguy cơ trong một thời gian dài đó làm tăng tỷ lệ mắc bệnh VQR ở người cao tuổi.

\section{KẾT LUẬN}

Các yếu tố nguy cơ như sự có mặt của một số vi khuẩn gây bệnh, tình trạng hút thuốc lá, tuổi...có liên quan chăăt chẽ với sự khởi phát và tiến triển của bệnh viểm quanh răng. Những yếu tố này có thể được coi là yếu tố chỉ điểm cho mức độ trầm trọng của bệnh VQR và được sử dụng để tiên lượng cho kết quả điều trị bệnh.

\section{TÀI LIẸU THAM KHẢO}

1. American Academy of Periodontitis (2000) "Parameter on Chronic periodontitis with advanced loss of periodontal support", J. Periodontol, 71, pp. 856-858.

2. Martha E.N. (2003), "Understanding the etiology of periodontitis: an overview of periodontal risk factors", Periodontology 2000, 32, pp. 11-23.

3. Armitage G.C (2004), "Periodontal diagnoses and classification of periodontal diseases", Periodontology 2004, Vol. 34, pp. 9-21.

4. Rivera-Hidalgo F. (2003), "Smoking and periodontal disease", Periodontology 2000, Vol.32, pp. 50-58.

5. Van Winkelhoff A., Bosch-Tijhof C.J., Winkel E.G., Van der Reijden W.A. (2001), "Smoking affects the Sub-gingival Microflora in Periodontitis", J. Periodontol, 72, pp. 666-671.

6. Torrungruang $K$, Bandhaya $P$ et al (2009), "Relationship between the presence of certain bacteria pathogens and periodontal status of urban Thai adults", J periodontol 2009;80:122-129.

\title{
MộT Số YẾU Tố LIÊN QUAN ĐẾN HIỆU QUẢ CỦA ATOSIBAN TRONG ĐIỀU TRI DỌA ĐỂ NON TẠI BỆNH VIỆN PHỤ SẢN TRUNG ƯƠNG
}

Nguyễn Mạnh Thắng*

\section{TÓM TẮT}

Mục tiêu: Mô tả một số yếu tố liên quan đến hiệu quả giảm co của Atosiban trong điêu trị dọa đẻ non tại Bệnh viện Phụ sản Trung Ương. Đối tượng và phương pháp: Nghiên cứu mô tả, hồi cứu nhằm mô

*Trường Đại học Y Hà Nội

Chịu trách nhiệm chính: Nguyễn Mạnh Thắng

Email: bsnguyenmanhthang@gmail.com

Ngày nhận bài: 2/4/2021

Ngày phản biện khoa học: 16/4/2021

Ngày duyệt bài: 19/5/2021 tả một số yếu tố liên quan đến hiệu quả giảm co của Atosiban trong điều trị dọa đẻ non ở thai phụ. Kết quả: Trẻ có cân nặng lúc sinh càng cao thì tỷ lệ điều trị thành công càng tăng $(p<0,05)$, Chỉ số Apga trong nhóm $>7$ tại phút thứ nhất và thứ 5 có tỷ lệ điều trị thành công cao hơn $(p<0,05)$, sản phụ nhập viện điều trị sớm hơn có tỷ lệ điêu trị thành công cao hơn $(p<0,05)$. Kết luận: Kết quả sẽ này góp phần quan trong trong việc định hướng điều trị của các bác sĩ lâm sàng.

Tư khóa: Đẻ non, Atosiban, Yếu tố liên quan

SUMMARY 
RISK FACTOR ON THE EFFICACY OF ATOSIBAN IN THE TREATMENT OF THREATENING PRETERM LABOR IN NATIONAL HOSPITAL OF OBSTETRICS AND GYNECOLOGY

Objective: Describes several factors related to Atosiban shrink-reducing effect in the treatment of threatening preterm labor in national hospital of Obstetrics and Gynecology. Subjects and methods: A descriptive study, retrospective to determine the effect of Atosiban contraction in the treatment of threatening preterm labor in pregnant women. Result: The higher birth weight children had, the higher the success rate of treatment $(p<0.05)$, the Apgar index in the group $>7$ at the first and fifth minutes had a higher success rate $(p<0.05)$, women who were admitted to hospital for treatment earlier had a higher success rate $(p<0.05)$. Conclustion: This result will significantly contribute to the direction of the treatment of clinicians.

Keyword: Preterm labor, Atosiban, Risk factor

\section{I. ĐĂT VẤN ĐỀ}

Đẻ non đã và đang là một trong những vấn đề y tế được quan tâm hàng đầu ở nước ta cũng như trên toàn thế giới. Đẻ non xảy ra ở khoảng $5-15 \%$ tổng số những trường hợp sinh. Trẻ đẻ non có nguy cơ mắc bệnh cao và tỷ lệ tử vong chu sinh càng cao khi tuổi thai càng nhỏ, với tỷ lệ vào khoảng 6 - 7\% số trường hợp sinh ở các nước đã phát triển. Số liệu toàn câuu ước tính trong năm 2001 có khoảng 24\% trẻ sơ sinh tử vong do nguyên nhân non tháng [1]. Sinh non cũng là nguyên nhân nhập viện phố biến, nhất là ở các nước phát triển[2]. Mặc dù đã có rất nhiều các biện pháp điều trị đã được áp dụng nhưng tỷ lệ sinh non vấn ít thay đổi trong 40 năm qua [3].

Việc sử dụng các thuốc giảm co để ức chế sự co bóp của tử cung đã và đang là phương pháp được áp dụng rộng rãi hiện nay. Có rất nhiều thuốc giảm co đang được dùng như: Spasfon, Magnesium Sulfate, Béta-mimetic, Nifedipin... tuy có hiệu quả nhưng lại có nhiều tác dụng phụ cũng như cách sử dụng phức tạp làm cho việc điều trị có thể bị gián đoạn hoặc không có kết quả.

Hiện nay việc sử dụng Atosiban, biệt dược Tractocile, là một chất cạnh tranh với receptor của oxytocin ở cơ tử cung, trong việc ngăn chặn các cơn co tử cung đang được thực hiên nhiều trong thực tiễn lâm sàng do tỷ lệ tác dụng phụ của thuốc trên sản phụ và thai nhi thấp hơn so với các thuốc giảm co khác [4]. Các nghiên cứu cho thấy một sự gia tăng có ý nghĩa thống kê số lượng thai phụ vẩn duy trì được thai kỳ tối thiểu 48 hà trong vòng 7 ngày kể từ ngày bắt đầu điều trị Atosiban [5]. Tuy nhiên hiện tại chưa có nhiều nghiên cứu về các mối liên quan tác động đến hiệu quả điều trị của liệu pháp điều trị này, do đó chúng tôi thực hiên nghiên cứu với mục tiêu "Mô tả một số yếu tố liên quan đến hiệu quả giảm co của Atosiban trong điều trị dọa đẻ non tại Bệnh viện Phụ sản Trung Ương"

\section{II. ĐỐI TƯỢNG VÀ PHƯƠNG PHÁP NGHIÊN CỨU}

2.1. Đối tượng nghiên cứu. Thai phụ được chẩn đoán và điều trị dọa đẻ non tại bệnh viện Phụ sản Trung ương.

Tiêu chuẩn lựa chọn. Có tuổi thai từ 28 đến 34 tuần. Có các dấu hiệu của dọa đẻ non: cơn co tử cung gây đau tần số 2 trở lền; ra máu hoặc ra dịch nhầy hồng âm đạo; tử cung đã xóa $>50 \%$ và mở từ $1 \mathrm{~cm}$ trở lên.

Tiêu chuẩn loại trừ: Các bệnh lý của tử cung: tử cung dị dạng, tử cng đôi. Thai bệnh lý: thai dị dạng, thai chết lưu... Bất thường về phần phụ của thai: ối đã võ̃, rau bong nonMẹ có các bệnh lý buộc phải lấy thai ngay: sản giật, hội chứng HELLP.

2.2. Phương pháp nghiên cứu

Thiết kế nghiên cứu: Nghiên cứu mô tả, hồi cứu

Cỡ mẫu và phương pháp chọn mẫu

Cỡ mẫu: Áp dụng công thức tính cỡ mẫu cho một tỷ lệ

$$
\mathrm{n}=\mathrm{Z}^{2}(1-\mathrm{a} / 2) \frac{\mathrm{p}(1-\mathrm{p})}{(\mathrm{p} z)^{2}}
$$

Trong đó: N: là số bệnh nhân càn nghiên cứu; $\mathrm{p}$ : là tỷ lệ thành công điêu trị doạ đẻ non theo nghiên cứu của $p=0,79$ theo nghiên cứu của $\mathrm{H}$. Helmer, M. Brunbauer và K. Rohrmeister[6].

Z: là độ tin cậy của xác suất với $a=0,05$ thì $\mathrm{z}=1,96$ : là sai số.

Ta lấy $\varepsilon_{=10}$. Thay vào công thức ta có cõ mẫu là 102 đối tượng. Trên thực tế chúng tôi lấy $\mathrm{N}=110$ bệnh nhân.

Phương pháp chọn mẫu: Nghiên cứu thực hiện phương pháp chọn mẫu thuận tiện

\subsection{Biến số nghiên cứu}

- Hiệu quả điều trị: Điêu trị thành công, thất bạo gồm các tiêu chí

Thành công: 1) Cơn co tử cung giảm hoặc mất, tim thai tốt. 2)Kéo dài được tuổi thai trên 48 giờ.

Thất bại: 1) Cơn co không giảm hoặc tăng. 2) Trên bệnh nhân có các tác dụng phụ mà bệnh nhân không chiu đưng được. 3) Phải chuyển sang phác đồ khác hoặc cuộc đẻ diễn ra trong vòng 48 giờ.

- Các yếu tố nguy cơ: Số lượng thai, tuổi thai, cân nặng lúc sinh, chỉ số Apga.

2.4. Xử lý, phân tích số liệu. Số liệu được phân tích bằng phần mềm SPSS 22.0. Sử dụng tần số, tỷ lệ \% nhằm mô tả cho biến định tính, 
sử dụng test Chi-2 để xác định các yếu tố liên quan hiệu quả điều trị.

2.5. Đạo đức nghiên cứu. Đề cương được phê duyệt bởi Hội đồng bảo vệ đề cương cao học thông qua. Nghiên cứu được Ban giám đốc, Hội đồng Khoa học Kỹ thuật và Hội đồng $Y$ đức của Bệnh viện Phụ sản Trung ương đồng ý.

\section{KẾT QUẢ NGHIÊN CỨU}

Nghiên cứu được tiến hành trên 110 đối tượng, trong đó $62,7 \%$ bà me mang đơn thai, $62,7 \%$ bà mẹ có tuối thai trong tuần thứ $20-$ 30 , trẻ sau sinh có cân nặng chủ yếu thuộc hau nhóm 2500 - 3000gram (44,5\%) và > 3000 gram $(25,4 \%)$, chí số Apga ở phút thứ nhất trong nhóm $>7$ có tỷ lệ $84,55 \%$ và ở phút thứ 5 trong nhóm $>7$ có tỷ lệ $97,27 \%$. Đa phần đối tượng nghiên cứu vào viện vào thời điểm trên 24 giờ. Hiệu quả điều trị thành công cắt cơn co tử cung $>48$ giờ của Atosiban là $87,5 \%$.

Bảng 1. Mối liên quan giữa số lượng thai và tác dụng giảm co của Atosiban

\begin{tabular}{|c|c|c|c|c|}
\hline Số lượng thaî Hiệu quả & $\begin{array}{l}\text { Thành công } \\
\text { n (\%) }\end{array}$ & $\begin{array}{l}\text { Thất bại } \\
\text { n (\%) }\end{array}$ & $\begin{array}{l}\text { Tống } \\
\text { n (\%) }\end{array}$ & p \\
\hline Đơn thai & $62(89,8)$ & $7(10,2)$ & $69(100)$ & \multirow{2}{*}{0,4} \\
\hline Song thai & $33(80,4)$ & $8(19,6)$ & $41(100)$ & \\
\hline
\end{tabular}

Nhận xét: Trong nhóm sản phụ dọa đẻ non có đơn thai tỷ lệ cắt cơn co thành công là: $89,8 \%$, cao hơn ở nhóm song thai $(80,4 \%)$, tuy nhiên sự khác biệt không có ý nghĩa thống kê với p> 0,05.

Bảng 2. Mối liên quan giữa tuối thai lúc vào viện và hiệu quả của Atosiban

\begin{tabular}{|c|c|c|c|c|}
\hline \begin{tabular}{|ll} 
Tuổi thai (tuân) & Tác dụng \\
\end{tabular} & $\begin{array}{l}\text { Thành công } \\
\text { n (\%) }\end{array}$ & $\begin{array}{l}\text { Thất bại } \\
\text { n (\%) }\end{array}$ & $\begin{array}{c}\text { Tống số } \\
\text { n (\%) }\end{array}$ & p \\
\hline $28-30$ & $60(86,9)$ & $9(13,1)$ & $69(100)$ & \multirow[b]{2}{*}{0,1} \\
\hline $31-34$ & $35(85,3)$ & $6(14,7)$ & $41(100)$ & \\
\hline
\end{tabular}

Nhận xét: Tuối thai từ 28 - 30 tuần có tỷ lệ cắt con co thành công là 86,9\%; tuối thai từ $31-34$ tuần có tỷ lệ cắt con co thành công là $85,3 \%$. Sự khác biệt không có ý nghĩa thống kê với $p>0,05$.

Bảng 3. Liên quan giữa tác dụng giảm co của Atosiban và trọng lượng của trẻ khi đẻ

\begin{tabular}{|c|c|c|c|c|}
\hline Cân nặng Tác dụng & $\begin{array}{l}\text { Thànhcông } \\
\text { n (\%) }\end{array}$ & $\begin{array}{l}\text { Thất bai } \\
\text { n (\%) }\end{array}$ & $\begin{array}{l}\text { Tống } \\
\text { n (\%) }\end{array}$ & p \\
\hline$<1500$ & 0 & $4(100)$ & $4(100)$ & \multirow{5}{*}{0,001} \\
\hline $1500-2000$ & $7(58,3)$ & $5(41,7)$ & $12(100)$ & \\
\hline $2100-2400$ & $11(64,7)$ & $6(35,3)$ & $17(100)$ & \\
\hline $2500-3000$ & $49(100)$ & 0 & $49(100)$ & \\
\hline$>3000$ & $28(100)$ & 0 & $28(100)$ & \\
\hline
\end{tabular}

Nhận xét: Tất cả trường hợp giữ thai thành công đều có trọng lượng thai $>1500$ gr. Tất cả những trường hợp giảm co thất bại đều có trọng lượng thai < 2500gr. Sự khác biệt có ý nghĩa thống kê giữa hai nhóm kết quả điêu trị p $<0,05$.

Bảng 4. Liên quan giữa hiệu quả giảm co của Atosiban và Apga của trẻ sau đẻ

\begin{tabular}{|c|c|c|c|c|c|}
\hline \multicolumn{2}{|l|}{ Chỉ số } & $\begin{array}{c}\text { Thành công } \\
\text { n (\%) }\end{array}$ & $\begin{array}{c}\text { Thất bại } \\
\text { n (\%) }\end{array}$ & $\begin{array}{c}\text { Tông } \\
\text { n (\%) }\end{array}$ & p \\
\hline \multirow{2}{*}{1 phút } & $<7$ & $8(8,42)$ & $9(60)$ & $17(15,45)$ & \multirow{2}{*}{0,04} \\
\hline & $>7$ & $87(91,58)$ & $6(40)$ & $93(84,55)$ & \\
\hline \multirow{2}{*}{5 phút } & $<7$ & $0(0)$ & $3(20)$ & $3(2,73)$ & \multirow{2}{*}{0,02} \\
\hline & $>7$ & $95(100)$ & $12(80)$ & $107(97,27)$ & \\
\hline
\end{tabular}

Nhận xét: Apgar phút thứ nhất trong nhóm >7 điểm của những trường hợp giảm co thành công chiếm $91,58 \%$, lớn hơn ở nhóm thất bại (40\%). Sự khác biệt có ý nghĩa thống kê với $p<0,05$. Apgar phút thứ 5 trong nhóm $>7$ điểm của những trường hợp giảm co thành công chiếm $100 \%$, lớn hơn ở nhóm thất bại (80\%). Sự khác biệt có ý nghĩa thống kề với $p<0,05$.

Bảng 5. Liên quan giữa thời điểm vào viện của sản phụ và hiệu quả giảm co của Atosiban

\begin{tabular}{|c|c|c|c|c|}
\hline Thời điểm vào viện Tác dụng & $\begin{array}{c}\text { Thành công } \\
\text { n (\%) }\end{array}$ & $\begin{array}{c}\text { Thất bại } \\
\text { n (\%) }\end{array}$ & $\begin{array}{l}\text { Tống } \\
\text { n (\%) }\end{array}$ & p \\
\hline$<24 \mathrm{~h}$ & $27(96,4)$ & $1(3,6)$ & $28(100)$ & \multirow{3}{*}{0,04} \\
\hline $24-48 \mathrm{~h}$ & $37(88)$ & $5(12)$ & $42(100)$ & \\
\hline$>48 \mathrm{~h}$ & $31(77,5)$ & $9(22,5)$ & $40(100)$ & \\
\hline
\end{tabular}

Nhận xét: Những trường hợp đến trước $24 \mathrm{~h}$ tỷ lệ thành công là $96,4 \%$; đến từ $24-48 \mathrm{~h}$ là $88 \%$ và sau 48 h là $77,5 \%$. Sự khác biệt có ý nghĩa thống kê với $p<0,05$. 


\section{BÀN LUẬN}

Trong nhóm sản phu dọa đẻ non có đơn thai tỷ lệ cắt cơn co thành công là: $89,8 \%$, cao hơn ở nhóm song thai $(80,4 \%)$, tuy nhiên sự khác biệt không có ý nghĩa thống kê vói $p>0,05$. Kết quả của chúng tôi cũng tương tự như của tác giả Phạm Thị Ngọc Điệp tỉ lệ duy trì thai kỳ được 48 giờ ở nhóm đơn thai là 93,1\% cao hơn nhóm song thai là $72,7 \%$ [7]. Như đã biết song thai rõ ràng là một yếu tố nguy cơ cũng như làm xấu thêm tiên lượng giữu thai do cơ chế làm căng dãn cơ tử cung quá mức, chính vì vậy hiệu quả giảm co giữ thai 48h của Atosiban trên nhóm song thai kém hơn hẳn nhóm đơn thai cũng dễ hiểu [8].

Tuồi thai khác nhau có hiệu quả điều trị của thuốc khác nhau. Theo Jannet D tuổi thai càng lớn thì tính dễ bị kích thích của cơ tử cung càng tăng lên, tử cung dễ nhạy cảm với các chất gây co tử cung như Oxytocin nội sinh, tuy nhiên kết quả của chúng tôi không tuân theo quy luật trên bởi tính chất đặc biệt của nhóm đối tượng nghiên cứu của chúng tôi phần lớn là những thai phụ có tuổi thai thấp và mức độ dọa đẻ non khá nặng nề mới được xét sử dụng cắt cớn co bằng Atosiban. Kết quả nghiên cứu cho thây tỷ lệ cắt cơn co thành công ở nhóm tuổi thai 28- 32 tuần là $86,9 \%$ cao hơn ở nhóm tuổi thai 32 - 34 tuần là $85,3 \%$, tuy nhiên sự khác biệt này không có ý nghĩa thống kê.

Một trong những yếu tố giúp đánh giá cho sự thành công của thuốc là chất lượng sống của trẻ sau sinh. Kết quả nghiên cứu cho thấy tất cả những trường hợp giảm co thất bại đều có trọng lượng thai < $2500 \mathrm{gr}$. Trong nhóm có trọng lượng thai từ 1500-2000gr thì giảm co thành cồng chiếm $58,3 \%$ còn thất bai chiếm $41,7 \%$. Trong nhóm có trong lượng thai 2500 - $3000 \mathrm{gr}$ thì giảm co thành công chiếm $64,7 \%$ còn giảm co thất bại chiếm $35,3 \%$. Điều này chúng tôi cũng cho là phù hợp vì trọng lượng thai tăng nhanh ở những tháng cuối của thời kỳ thai nghén. Tuy nhiên nghiên cứu của chúng tôi có tỷ lệ cân nặng trung bình của thai nhi thấp hơn so với một số tác giả khác cũng có thể do trước đây các tác giả lựa chọn mốc 38 tuần để đánh giá là thai đủ tháng nhưng trong nghiên cứu chúng tôi lựa chọn mốc <37 tuần để chẩn đoán là thai đủ tháng.

Trẻ sơ sinh non tháng sau đẻ có nguy cơ suy hô hấp rất cao. Suy hô hấp sơ sinh là một biến chứng phổ biến và rất nguy hiểm nhất là khi tuổi thai nhỏ. Kết quả cho thấy trong 110 trường họp được dùng Atosiban để điều trị và được theo dõi đến lúc đẻ có: Apgar phút thứ nhất $>7$ điểm của những trường hợp giảm co thành công chiếm
$91,58 \%$, lớn hơn ở nhóm thất bại $(40 \%)$. Sự khác biệt có ý nghĩa thống kê với p $<0,05$. Apgar phút thứ $5>7$ điểm của những trường hợp giảm Co thành công chiếm $100 \%$, lớn hơn ở nhóm thất bại (80\%). Sự khác biệt có ý nghĩa thống kê với $p<0,05$.

Những trường hợp đến trước $24 \mathrm{~h}$ có 28 trường hợp tỷ lệ thành công là $96,4 \%$. Đặc biệt có 11 trường hợp đến ngay trong vài giờ xuất hiện triệu chứng dọa đẻ non đã giữ thai được đển đủ tháng. Đến từ $24-48$ h có 42 trường hợp và tỷ lệ thành công là $88 \%$. Đến sau 48 h có 40 trường hợp, tỷ lê thành công là $77,5 \%$. Sự khác biệt có ý nghĩa thống kê với $p<0,05$. Trong hầu hểt các nghiên cứu của nước ngoài không đề cập đến vấn đề này vì ở các nước phát triển trình độ dân trí cao, cũng như công tác y tế ban đầu rất tiến bộ nên các thai phụ luôn đến viện ngay khi mới có các triệu trứng dọa đẻ non. Một số nghiên cứu ở trong nước có kết quả khác nhau cũng một phàn do nguyên nhân này.

\section{KẾT LUÂ̂N}

Nghiên cứu xác định được các mối liên quan đến hiệu quả điều trị như cân nặng sơ sinh của trẻ, chỉ số Apga phút thứ 1 và phút thứ 5 , thời gian vào viện của sản phụ. Kết quả sẽ này góp phần quan trong trong việc định hướng điêu trị của các bác sĩ lâm sàng.

\section{TÀI LIỆU THAM KHẢO}

1. Darmstadt GL, Lawn JE, Costello A (2003). Advancing the state of the world's newborns. Bulletin of the World Health Organization, 81(3), 224-225.

2. Savitz DA, Blackmore CA, Thorp JM (1991), Epidemiologic characteristics of preterm delivery: etiologic heterogeneity. American journal of obstetrics and gynecology, 164(2), 467-471.

3. Papatsonis DN, Kok JH, van Geijn HP et al (2000). Neonatal effects of nifedipine and ritodrine for preterm labor. Obstetrics and gynecology, 95(4), 477-481.

4. Papatsonis D, Flenady V, Cole S et al (2005). Oxytocin receptor antagonists for inhibiting preterm labour. The cochrane database of systematic reviews, (3), Cd004452.

5. Gyetvai $K$, Hannah ME, Hodnett ED et al (1999). Tocolytics for preterm labor: a systematic review. Obstetrics and gynecology, 94(5 Pt 2), 869-877.

6. Helmer $H$, Brunbauer $M$, Rohrmeister $K$ (2003). Exploring the role of Tractocile in everyday clinical practice. BJOG : an international journal of obstetrics and gynaecology, 110 Suppl 20, 113-115.

7. Phạm Thị Ngọc Diệp (2010). Đánh giá hiệu quả điêu tri của ATOSIBÂN trong điêu tri doa sanh non tại Bệnh viện Từ Dũ. Hội nội tiết sinh sản và vô sinh thành phố Hồ Chí Minh. 